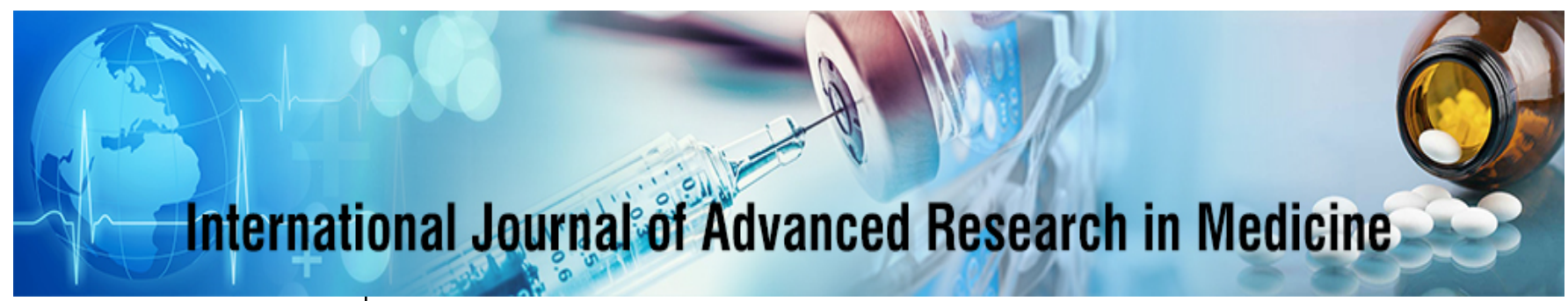

E-ISSN: 2706-9575

P-ISSN: 2706-9567

IJARM 2021; 3(1): 220-222

Received: 15-09-2020

Accepted: 17-10-2020

\section{Kaur Harmeet}

Assistant Professor,

Department of Anatomy,

Kanti Devi Medical College,

Hospital and Research Centre,

Akbarpur, Mathura,

Uttar Pradesh, India
Corresponding Author:

Kaur Harmeet

Assistant Professor,

Department of Anatomy,

Kanti Devi Medical College,

Hospital and Research Centre,

Akbarpur, Mathura,

Uttar Pradesh, India

\section{The histological difference between adult cadaveric ureter and full term human fetal ureter: A histological study in India}

\section{Kaur Harmeet}

DOI: https://doi.org/10.22271/27069567.2021.v3.i1d.142

\begin{abstract}
Introduction: This study can contribute significantly to understand the histological differences of the anatomical ureter in human adult and human featus. This data will be useful for anatomist ,forensic expert and pathologist. The ureter truly commands a rather unique position in gross anatomy, owing chiefly to its ever-changing intemallining and its highly specialized muscular coatings.

Aim: The aim of this histological study was to determine the histological differences of the anatomical ureter in human adult and human featus.

Material and Method: tissue samples were taken from proximal, middle and distal regions of ureter od human adult cadaver and human featues and stained with $\mathrm{H} \& \mathrm{E}$. The histology of the ureter showed considerable differences among various anatomical regions of the ureter. No significant sex-based differences were found.

Result \& Conclusion: The ureter were composed of tunica mucosa, submucosa, muscularis and serosa both in human adult and featus. this study can contribute to understand the congenital diseases such as agenesis, hypoplasia of ureter etc.
\end{abstract}

Keywords: ureter, epithelium, H\&E stain

\section{Introduction}

The ureters have been identified for at least two thousand years, with the word "ureter" stemming from the stem uro-relating to urinating and seen in written records since at least the time of Hippocrates ${ }^{[1]}$. The ureters are a component of the urinary system. Urine, produced by the kidneys, travels along the ureters to the bladder. It does this through regular contractions called peristalsis ${ }^{[2]}$. The upper aspect of the ureter lies in the abdomen while its continuing lower part is in the pelvis. The upper aspect of the ureter, known as the pelvis of the ureter, is thin walled and funnel-shaped in appearance. Emanating well within the sinus of the kidney, the pelvis of the ureter lies among the large renal vessels and is formed by the junction of usually two thin-walled tubes, the greater calyces. The greater calyces give off a number of small branches, the lesser calyces, that are short and increase in diameter as they approach the wall of the sinus to which they become attached. Their wide, funnel-like ends envelop the renal papillae and serve as a collecting area for urine. A longitudinal section of the kidney and pelvis of the ureter reveals that the lesser calyces are usually about eight in number, one calyx surrounding two to three papillae. Topographically viewed, the portion of the pelvis of the ureter that lies outside of the kidney has directly in front of it ${ }^{[3,4]}$. Recent work demonstrates most clearly that all was not totally known. Witness the very articulate studies of Hicks ${ }^{[7,8]}$, Hoyes et al. ${ }^{[12]}$ Dixon and Gosling ${ }^{[7]}$, and Firth and Hicks ${ }^{[8]}$

The ureters in neonates and infants can be anatomically and functionally so severely compromised as to warrent the term "dysplasia." Under light microscopy, poor muscularization and decreased muscle and connective tissue are present, as well as small and deformed muscle cells with nexuses that are markedly decreased or absent, and intracellular organelles that are poorly defined under electron microscopy. The ureters develop from the ureteric buds, which are outpouchings from the mesonephric duct. This is a duct, derived from mesoderm, found in the early embryo ${ }^{[5]}$. Over time, the buds elongate, moving into surrounding mesodermal tissue, dilate, and divide into left and right ureters. Eventually, successive divisions from these buds form not only the ureters, but also the pelvis, major and minor calyces, and collecting ducts of the kidneys ${ }^{[5]}$. 
These studies have brought to light numerous insights into the fine structure of the ureter, with specific highlights on cytologic physiologic, and neural considerations. Thus, as a result, we are now in a position to better explain several structure-function relationships of the ureter in health and disease.

\section{Aim}

My study was aimed at looking into the morphological and histological differences of ureter in adult and term human featus.

\section{Material and Method}

This study carried out in department of Anatomy, Himalayan Institute of Medical Sciences (HIMS), Swami Ram Nagar, Dehradun was based on microscopic examination of ureteric tissue of adult human and human featus. Tissue took from different gestational ages ranging from 37-40 week of fertilization and adult cadaveric ureter with no obvious abnormalities on macroscopic inspection. Tissue were taken after studying its external morphology then fixed in $10 \%$ formalin and later processed in paraffin wax. $5-7 \mu$ sections were prepared and stained with hematoxylin and eosin which were studied under the light microscope.

\section{Result}

The adult and featal ureters, viewed in situ, are the ducts that connect the kidneys to the urinary bladder. In the adult they were of a pale color, approximately $27 \mathrm{~cm}$ in length and in fetus $4 \mathrm{~cm}$ and were located in the extraperitoneal tissue behind the peritoneum, to which they closely adhere. histologic preparations of the adult human ureter showing a faint color, and another, deeper part with fine granulations. The mucous membrane of the ureter is comprised of transitional epithelium, four to six cell layers thick, lacks a basement membrane, and rests upon a fibrous lamina propria. The first layer of the mucosal epithelium characteristeically contains large polygonal cells.

The lamina propria, which is continuous with the renal interstitial tissue, contains both elastic fibers and collagenous fibers.
At the lower end of the upper third of the adult ureter saw a developments in but not in the fetuses. In adult there appear some outer longitudinal muscle fibers bound into large masses at one side of the tube in this region. The circular muscle fibers are arranged in a thick layer with small clefts between them. This segment of the ureter also possesses a rather large number of inner longitudinal muscles which form a seemingly unbroken layer irrespective of the fact that each bundle is separated by connective tissue. Sections of the fetal ureter in lumbar regions depicted that the individual muscle fibres in the circular pattern ,coat became gradually closer to each other to form thicker muscle bundles. The middle aspect of the ureter in the adult (not in the featus) has three distinct layers: a well developed circular layer, a highly organized inner longitudinal layer, and a less welldeveloped but recognizable outer longitudinal layer of muscle.

At 37weeks the inner longitudinal muscle coat became slightly visible at focal areas in sections. At 40 weeks section of fetal ureter could be well visible and thicker well circulated then previous weeks at the lumber region. the inner longitudinal muscle coat became fully identifiy Sections from the lower $1 / 3$ of the ureter showed a delayed development in comparison to the middle 1/3. The transitional epithelium further progressed in development by increase in the number of layers to 7-8 and increase in the number of mucosal folds giving the shape of a typical star shaped lumen. Increase in thickness of the adventitious coat was also observed with increase in its vascularity. Sections observed from the intramural parts of the ureter These longitudinal muscle fibres were observed to with the superficial trigonal muscle at this stage also.

Adventitia was of variable thickness and is composed of areolar and fibroelastic connective tissue in adult ureter. The connective tissue does not follow any definite pattern. The lowermost aspect of the adult ureter, for a distance of 3 to 4 $\mathrm{cm}$, contains a specialized fibrous tissue cover possessing a group of longitudinal muscle fibers located on one side (Waldeyer's sheath).
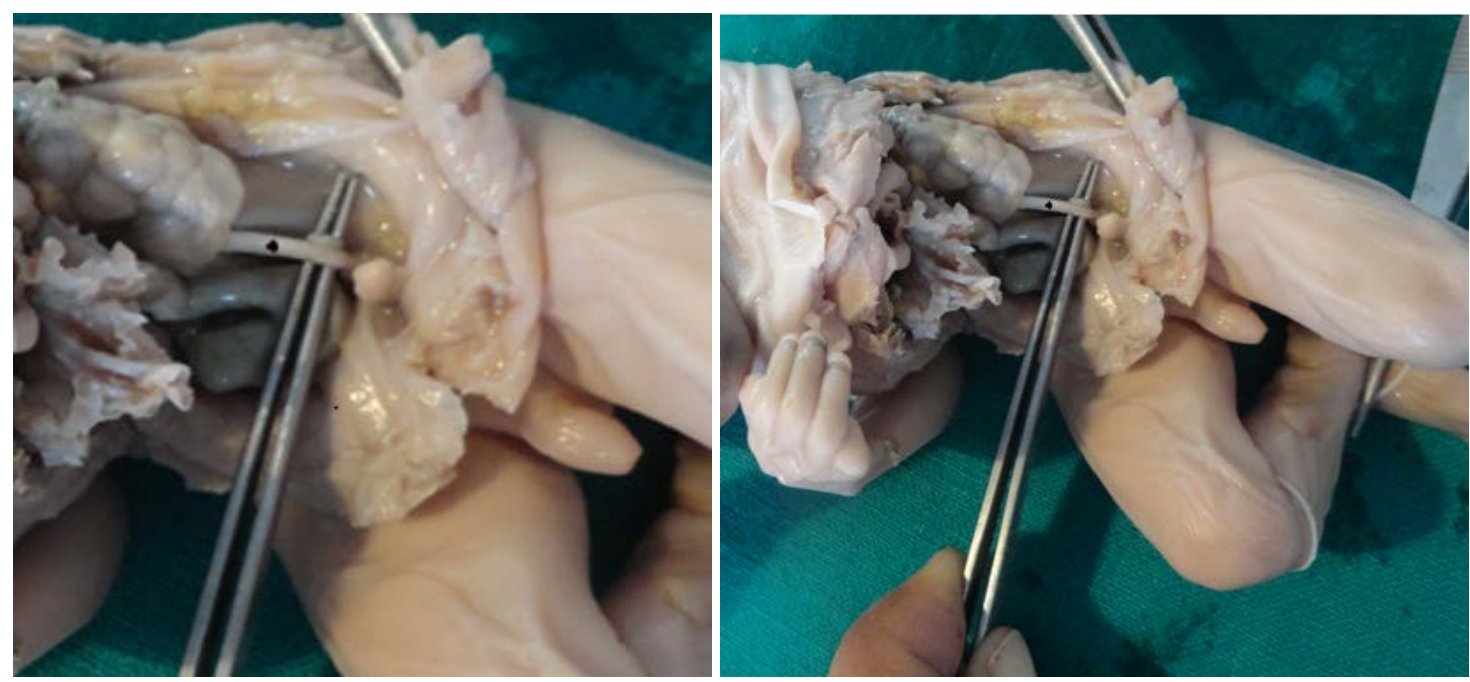

Fig 1: Featus abdomen opened and tissue taken from various parts of ureter 


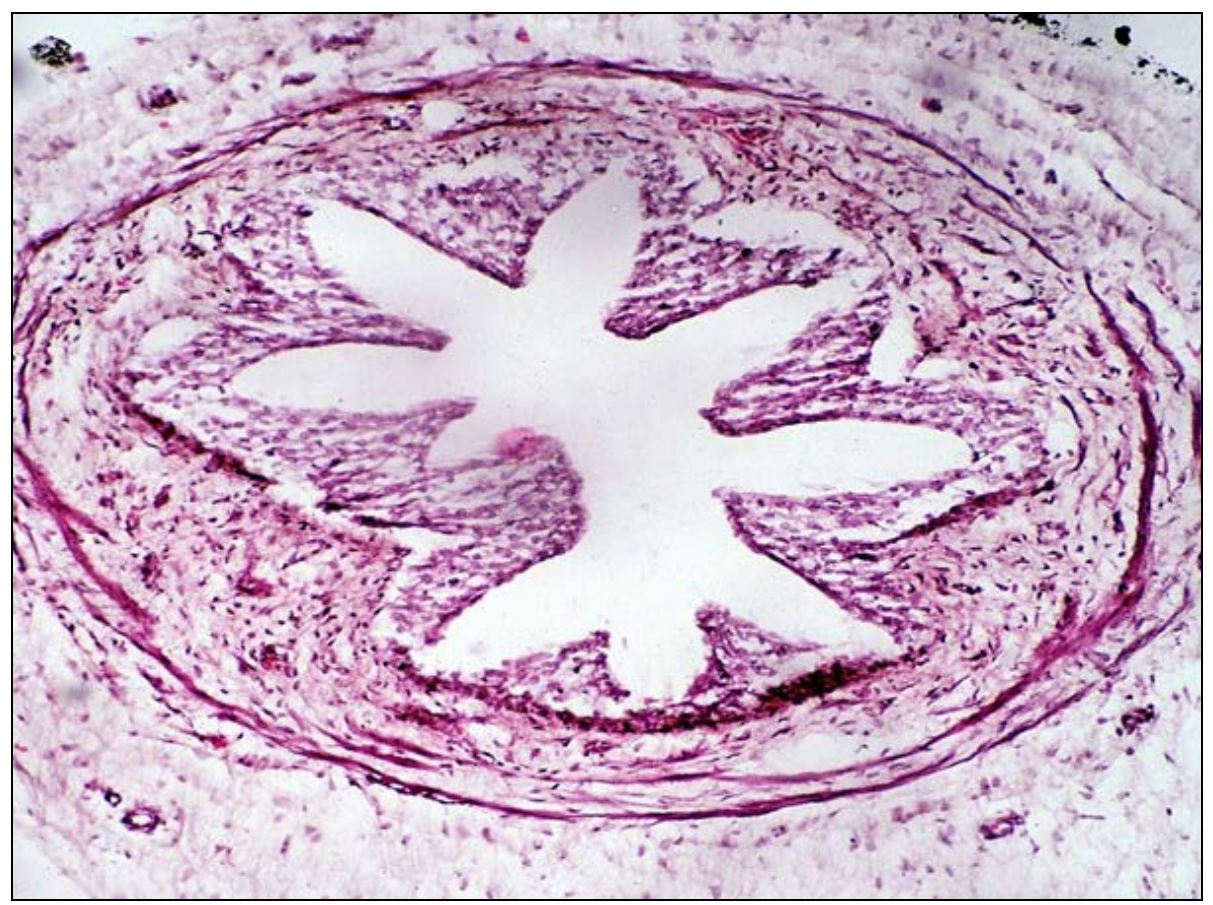

Fig 2: At $38^{\text {th }}$ week of gestational age showing transitional epitheliums cells vacuolated and polygonal in shape, submucosa, muscles and adventitia

\section{Discussion}

Recent work demonstrates most clearly that all was not totally known. Satani's [10] included observations which indicated that fewer polynuclear cells are found in the ureteral epithelium than in the epithelium of the bladder, and that the size of each cell is smaller than that of the bladder. Stein and Weinberg ${ }^{[11]}$, utilizing quantitative methods and specific stains for muscle and connective tissue, reported that the adult human ureter contains a much larger percentage of muscle than that of the featus and that in the normal process of aging the elastic fibers fray, fragment, and develop an increased affinity for calcium salts. They further determined that the amount of fibrous tissue in muscle increases as a result of obstruction. On the other hand, Tacciuoli $\mathrm{M}$ et al. ${ }^{[12]}$ reported that both longitudinal and oblique muscle fibres were present in the intravesical part of the ureter between 22 and 24 weeks. Most of these fascicles were present on the medial side of the intramural ureteric wall and some reached the mucous membrane of the bladder to terminate around the ureteric orifice

\section{Reference}

1. William J Larsen. Human Embryology. $3^{\text {rd }}$ edn. Philadelphia, Pennsylvania 19106: Chur chill Livingstone; Lowe, Alan Stevens, James S. (2005). Human histology (3rd ed.). Philadelphia \& Toronto: Elsevier Mosby 2001, 265-313, 324. ISBN 03230-3663-5.

2. Standring S. Urogenital System. Gray's Anatomy: The Anatomical Basis of Clinical Practice. $40^{\text {th }} \mathrm{edn}$. Churchill Livingstone Elsevier 2008, 1225-59.

3. Arthur D. Smith (Editor), Glenn Preminger (Editor), Gopal H. Badlani (Editor), Louis R. Kavoussi (Editor) Ureteral Anatomy". Smith's textbook of endourology (4th ed.). John Wiley \& Sons Ltd. 2019;38:455-464.
4. Lowe, Alan Stevens, James S. Human histology (3rd ed.). Philadelphia \& Toronto: Elsevier Mosby. 2005, 324.

5. Sadley TW. "Urinary system". Langman's medical embryology (14th ed.). Philadelphia: Wolters Kluwer. 2019, 256-266.

6. Dixon JS, Gosling JA. Histochemical and electron microscopic observations on the innervation of the upper segment of the mammalian ureter. J. Anat. Dixon, J.S 1971;110(57):8.

7. Gosling JA. The fine structure of pacemaker cells in the pig renal calyces. Anat. Rec. 1975;139:1973.

8. Firth JA, Hicks RM. Interspecies variation in the fine structure and enzyme cytochemistry of mammalian transitional epithelium. J. Anat 1973;116:31,

9. Firth JA, Hicks RM. Membrane specialization and synchronization cell death in developing rat transitional epithelium. J. Anat 1972;113:95.

10. Satani Y. Histological study of the ureter. J. Urol. 1919;3:247.

11. Stein J, Weinberg SR. A histologic study of the normal and dilated ureter. J. Urol. 1962;87:33

12. Hoyes AD, Bourne R, Martin BGH. Ultrastructure and distribution of the subepithelial nerves of the rat ureter. J. Anat 1974;117:210

13. Tacciuoli $M$, Lotti $T$, de Matteis A, Laurenti $C$. Development of the smooth muscle of the ureter and vesical trigone: histological investigation in human fetus. Eur Urol 1975;1(6):282-6. 